\title{
Advancing into the details of pulmonary haemodynamics during exercise
}

\author{
Gabor Kovacs ${ }^{1,2}$ and Horst Olschewski $i^{1,2}$
}

Affiliations: ${ }^{1}$ Medical University of Graz, Graz, Austria. ${ }^{2}$ Ludwig Boltzmann Institute for Lung Vascular Research, Graz, Austria.

Correspondence: Gabor Kovacs, Medical University of Graz, Auenbruggerplatz 20, 8036 Graz, Austria.

E-mail: gabor.kovacsaklinikum-graz.at

@ERSpublications

Recent clinical studies allow better understanding of changes in pulmonary haemodynamics during exercise in different disease entities http://ow.ly/129030lwHP2

Cite this article as: Kovacs G, Olschewski $\mathrm{H}$. Advancing into the details of pulmonary haemodynamics during exercise. Eur Respir J 2018; 52: 1801578 [https://doi.org/10.1183/13993003.01578-2018].

Science never solves a problem without creating ten more (George Bernard Shaw)

Pulmonary haemodynamics during exercise may help us to understand why patients are severely limited despite relatively moderate pathological findings at rest. Recently, a European Respiratory Society task force presented the expert consensus on clinical experience and published studies over the past 50 years in this field [1], and suggested a definition of "exercise pulmonary hypertension" (exercise PH). In contrast to previous guidelines [2], this expert statement does not consider an isolated increase of mean pulmonary arterial pressure (MPAP) over a certain threshold during exercise as pathological. Instead, "exercise $\mathrm{PH}^{\text {" is }}$ characterised by an excessive increase of MPAP in relation to the increase in pulmonary blood flow during exercise. This basically corresponds to a pressure/flow slope. Mainly based on a recent study evaluating exercise haemodynamics in subjects with and without known cardiac and pulmonary vascular disease [3], exercise $\mathrm{PH}$ is suggested if MPAP increases above $30 \mathrm{mmHg}$, but only if total pulmonary resistance (TPR) also surpasses 3 Wood units during maximal exercise. As TPR is calculated as MPAP/cardiac output, subjects with both high MPAP and high cardiac output levels will not meet the criteria. Alternatively, it has been suggested that analysis of the steepness of the MPAP/cardiac output slope can identify subjects with an abnormal haemodynamic reaction during exercise [4]. These considerations have led to several new questions waiting for answers and opened the door for investigations on the clinical relevance of pulmonary haemodynamics during exercise [5-8].

In the current issue of the European Respiratory Journal, GuTH et al. [9] drive our attention to a condition of special interest in regard to the pulmonary pressure-flow relationship: chronic thromboembolic disease (CTED), i.e. a disease similar to chronic thromboembolic pulmonary hypertension, but with resting MPAP below $25 \mathrm{mmHg}$. The study revealed that a large proportion of severely symptomatic CTED patients (in their cohort 75\%) fulfilled the suggested criteria of exercise $\mathrm{PH}$, and presented with a steep MPAP/cardiac output slope $\left(3.6 \pm 1.0 \mathrm{mmHg} \cdot \mathrm{L}^{-1} \cdot \mathrm{min}\right)$. These haemodynamic features may explain why patients with CTED typically suffer from severe respiratory symptoms, despite mild resting haemodynamic findings.

The study of GUTH et al. [9] also addresses the question of how thrombendarterectomy in CTED changes pulmonary haemodynamics. After the operation, CTED patients showed a significant improvement in exercise capacity and quality of life as well as their pulmonary haemodynamics. Particularly during exercise, the TPR values and their MPAP/cardiac output slope $\left(2.3 \pm 0.8 \mathrm{mmHg} \cdot \mathrm{L}^{-1} \cdot \mathrm{min}\right)$ improved considerably as 
compared to pre-operative values. This offers a potential explanation why CTED patients benefit so much from thrombendarterectomy, despite little decrease of resting MPAP (from 20 to $17 \mathrm{mmHg}$ ). These data are encouraging and are in line with the results of previous pilot studies in patients with systemic sclerosis showing positive effects of pulmonary arterial hypertension (PAH) drugs on exercise haemodynamics, despite little or no effect on resting haemodynamics [10-12].

In spite of this and other recent important contributions in the field, many questions regarding exercise haemodynamics remain to be answered. Some methodological details regarding the optimal assessment of haemodynamic variables are still under discussion [13-16], and the associations between exercise haemodynamics and vascular properties are just starting to be analysed $[17,18]$.

In addition, we still need to better recognise and understand the causes of exercise $\mathrm{PH}$. There are three major causes explaining an excessive MPAP increase in relation to flow during exercise. Patients with left heart diseases develop strongly elevated left cardiac and pulmonary arterial wedge pressure (PAWP) values during exercise resulting in a strong increase in pulmonary arterial pressure. In contrast, post-capillary pressures and PAWP remain low in patients with diseases of the pre-capillary pulmonary arteries. Finally, in patients with airway or lung diseases, an increase of intrathoracic pressures during exercise may be the reason for a steep increase in right atrial pressure, MPAP and PAWP. In theory, cardiac, pulmonary, or pulmonary vascular limitations may be distinguished, but in reality, differences in haemodynamic patterns may often be difficult to recognise and, of course, combinations of these conditions may occur. Studies for improved delineation of these patients are needed, as potential therapeutic opportunities may primarily depend on the underlying condition.

Another open question is whether exercise $\mathrm{PH}$ is predictive for the development of manifest pulmonary hypertension. Systemic sclerosis is often considered as a model to investigate the development of pulmonary hypertension and some studies suggest that exercise $\mathrm{PH}$ may represent an early pulmonary vascular involvement and predict manifestation of PAH [19-21]. This might be also the case in patients with CTED [22], but only long-term follow-up studies could answer this question.

Beyond all these considerations, however, one question appears to be most important: is exercise $\mathrm{PH}$ prognostically relevant? A small study supported this hypothesis [23] and a large, prospective multicentre international trial is currently on the way. Hopefully, this study will be soon completed and will give us the opportunity to better understand the links between pathophysiology, prognosis and symptoms: and the answers will surely create at least ten questions more...

Conflict of interest: G. Kovacs reports personal fees and non-financial support from Actelion, Bayer, GSK, MSD, Pfizer, AOP, Boehringer Ingelheim, Novartis and Chiesi, outside the submitted work. H. Olschewski reports grants from Bayer, Unither Pharmaceuticals, Actelion Pharmaceuticals Ltd, Roche, Boehringer Ingelheim and Pfizer Inc., personal fees from Gilead Sciences Inc., Encysive Pharmaceuticals Ltd and Nebu-Tec, personal fees and non-financial support from Bayer, Unither Pharmaceuticals, Actelion Pharmaceuticals Ltd, Pfizer Inc., Eli Lilly, Novartis, Astra Zeneca, Boehringer Ingelheim, Chiesi, Menarini, MSD and GSK, outside the submitted work.

\section{References}

1 Kovacs G, Herve P, Barbera JA, et al. An official European Respiratory Society statement: pulmonary haemodynamics during exercise. Eur Respir J 2017; 50: 1700578.

2 Galie N, Torbicki A, Barst R, et al. Guidelines on diagnosis and treatment of pulmonary arterial hypertension. The Task Force on Diagnosis and Treatment of Pulmonary Arterial Hypertension of the European Society of Cardiology. Eur Heart J 2004; 25: 2243-2278.

3 Herve P, Lau EM, Sitbon O, et al. Criteria for diagnosis of exercise pulmonary hypertension. Eur Respir J 2015; 46: 728-737.

4 Naeije R, Vanderpool R, Dhakal BP, et al. Exercise-induced pulmonary hypertension: physiological basis and methodological concerns. Am J Respir Crit Care Med 2013; 187: 576-583.

5 Voilliot D, Magne J, Dulgheru R, et al. Determinants of exercise-induced pulmonary arterial hypertension in systemic sclerosis. Int J Cardiol 2014; 173: 373-379.

6 Richter MJ, Sommer N, Gall H, et al. Pulmonary hemodynamic response to exercise in chronic thromboembolic pulmonary hypertension before and after pulmonary endarterectomy. Respiration 2015; 90: 63-73.

7 Degani-Costa LH, Levarge B, Digumarthy SR, et al. Pulmonary vascular response patterns during exercise in interstitial lung disease. Eur Respir J 2015; 46: 738-749.

8 Hilde JM, Skjorten I, Hansteen V, et al. Haemodynamic responses to exercise in patients with COPD. Eur Respir J 2013; 41: 1031-1041.

9 Guth S, Wiedenroth CB, Rieth A, et al. Exercise right heart catheterisation before and after pulmonary endarterectomy in patients with chronic thromboembolic disease. Eur Respir J 2018; 52: 1800458.

10 Kovacs G, Maier R, Aberer E, et al. Pulmonary arterial hypertension therapy may be safe and effective in patients with systemic sclerosis and borderline pulmonary artery pressure. Arthritis Rheum 2012; 64: 1257-1262.

11 Saggar R, Khanna D, Shapiro S, et al. Brief report: effect of ambrisentan treatment on exercise-induced pulmonary hypertension in systemic sclerosis: a prospective single-center, open-label pilot study. Arthritis Rheum 2012; 64: $4072-4077$. 
12 Segrera SA, Lawler L, Opotowsky AR, et al. Open label study of ambrisentan in patients with exercise pulmonary hypertension. Pulm Circ 2017; 7: 531-538.

13 Hsu S, Brusca SB, Rhodes PS, et al. Use of thermodilution cardiac output overestimates diagnoses of exercise-induced pulmonary hypertension. Pulm Circ 2017; 7: 253-255.

14 van Riel AC, Opotowsky AR, Santos M, et al. Accuracy of echocardiography to estimate pulmonary artery pressures with exercise: a simultaneous invasive-noninvasive comparison. Circ Cardiovasc Imaging 2017; 10: e005711.

15 Kovacs G, Avian A, Pienn M, et al. Reading pulmonary vascular pressure tracings. How to handle the problems of zero leveling and respiratory swings. Am J Respir Crit Care Med 2014; 190: 252-257.

16 Naeije R, Saggar R, Badesch D, et al. Exercise-induced pulmonary hypertension: translating pathophysiological concepts into clinical practice. Chest 2018; 154: 10-15.

17 Reddy YNV, Andersen MJ, Obokata M, et al. Arterial stiffening with exercise in patients with heart failure and preserved ejection fraction. I Am Coll Cardiol 2017; 70: 136-148.

18 Borlaug BA, Kane GC, Melenovsky V, et al. Abnormal right ventricular-pulmonary artery coupling with exercise in heart failure with preserved ejection fraction. Eur Heart J 2016; 37: 3293-3302.

19 Codullo V, Caporali R, Cuomo G, et al. Stress Doppler echocardiography in systemic sclerosis: evidence for a role in the prediction of pulmonary hypertension. Arthritis Rheum 2013; 65: 2403-2411.

20 Kusunose K, Yamada H, Hotchi J, et al. Prediction of future overt pulmonary hypertension by 6-min walk stress echocardiography in patients with connective tissue disease. J Am Coll Cardiol 2015; 66: 376-384

21 Voilliot D, Magne J, Dulgheru R, et al. Prediction of new onset of resting pulmonary arterial hypertension in systemic sclerosis. Arch Cardiovasc Dis 2016; 109: 268-277.

22 Donahoe L, Vanderlaan R, Thenganatt J, et al. Symptoms are more useful than echocardiography in patient selection for pulmonary endarterectomy. Ann Thorac Surg 2017; 104: 1179-1185.

23 Stamm A, Saxer S, Lichtblau M, et al. Exercise pulmonary haemodynamics predict outcome in patients with systemic sclerosis. Eur Respir J 2016; 48: 1658-1667. 